\title{
Author Correction: The inverse-trans-influence in tetravalent lanthanide and actinide bis(carbene) complexes
}

\author{
Matthew Gregson, Erli Lu, David P. Mills, Floriana Tuna, Eric J.L. Mclnnes, Christoph Hennig, \\ Andreas C. Scheinost, Jonathan McMaster, William Lewis, Alexander J. Blake, Andrew Kerridge \\ \& Stephen T. Liddle
}

Nature Communications 8:14137 doi: 10.1038/ncomms14137 (2017); Published 3 Feb 2017; Updated 5 Feb 2018

The original version of this Article contained a typographical error in Fig. 2, where reagent $\mathrm{H}_{2} \mathrm{C}\left(\mathrm{Ph}_{2} \mathrm{PNSiMe}_{3}\right)_{2}$ was incorrectly given as $\mathrm{H}_{2} \mathrm{C}(\mathrm{PNSiMe})_{2}$. This has now been corrected in both the PDF and HTML versions of the Article. 